\title{
Development of Niobium Oxide Coatings on Sand-Blasted Titanium Alloy Dental Implants
}

\author{
Allen C. Mackey ${ }^{1}$, Robert L. Karlinsey ${ }^{1}$, Tien-Mien G. Chu' ${ }^{2}$, Meoghan MacPherson ${ }^{2}$, Daniel L. Alge ${ }^{3}$ \\ ${ }^{1}$ Indiana Nanotech, Indianapolis, USA.; ${ }^{2}$ Department of Restorative Dentistry, Indiana University School of Dentistry, Indianapolis, \\ USA.; ${ }^{3}$ Weldon School of Biomedical Engineering, Purdue University, West Lafayette, USA. \\ Email: almackey@iupui.edu
}

Received February $5^{\text {th }}, 2012$; revised March $9^{\text {th }}, 2012$; accepted April $12^{\text {th }}, 2012$

\begin{abstract}
The purpose of this study was to use scanning electron microscopy (SEM) evaluation to determine the optimal anodizetion conditions needed to generate niobium oxide coatings on titanium alloy dental implant screws. Sand-blasted titanium alloy dental implants were anodized in dilute hydrofluoric acid $\left(\mathrm{HF}_{(\mathrm{aq})}\right)$ solution using a Sorensen DLM 300-2 power supply. The HF concentration and anodization time were varied and the resulting implant surfaces were evaluated using a Jeol JSM-5310LV Scanning Electron Microscope to determine the ideal anodization conditions. While HF is necessary to facilitate oxide growth, increasing concentrations resulted in proportionate increases in coating delamination. In a similar manner, a minimum anodization time of 1 hour was necessary for oxide growth but longer times produced more delamination especially at higher $\mathrm{HF}_{(\mathrm{aq})}$ concentrations. SEM imaging showed that implants anodized for 1 hour in a $0.1 \% \mathrm{HF}_{(\mathrm{aq})}$ aqueous solution had the best results. Anodization can be used to generate niobium oxide coatings on sand-blasted Ti alloy dental implants by balancing the competing factors of oxide growth and coating delamination. It is believed that these oxide coatings have the potential to improve osseointegration relative to untreated dental implants when evaluated in an in vivo study.
\end{abstract}

Keywords: Anodization; Niobium Oxide; Dental Implant; Scanning Electron Microscopy

\section{Introduction}

Dental implants are an important therapeutic approach, providing both an aesthetic and functional alternative to tooth replacement. Procedures involving dental implants have grown steadily, rising consistently over the last 20 years to reach approximately one million performed annually worldwide [1]. After endosseous implants are surgically inserted into the jaw bones, three outcomes are possible. Early implant failure will likely result from either of the first two outcomes, in which either an inflammatory response is triggered or a fibrous capsule of connective tissue forms around the implant. However, the third outcome, where living and functional bone tissue forms around the implant without an intervening layer of soft tissue, is critical for long-term patient success [2]. This is known as osseointegration and is typically defined as the intimate and direct apposition of bone growth onto the titanium (Ti) implant surface after it has interacted with biological tissues and fluids [3].

Despite the high success rates demonstrated in longitudinal studies (ranging from $85 \%$ to $100 \%$ in studies of up to 24 years [2]), many of the failures that still occur are largely attributed to insufficient osseointegration [4].
Attempts to improve osseointegration have led to more than 1300 types of commercially available oral implants [5] which vary in such qualities as material type, geometry, and surface properties. While delicate surgical techniques, prosthetic biomechanical factors and patient hygiene are all important for the clinical outcome [6], it is well-known that implant surface properties influence the potential for and subsequent extent of osseointegration. These properties, including roughness, composition, and hydrophilicity, are therefore a prime focal point of implant research. One of the more common surface property modifications is to roughen the Ti surface using a grit or sand-blasting technique. Compressed air is used to project high-velocity ceramic particles, such as alumina, titanium dioxide, and calcium phosphate $(\mathrm{CaP})$, at the implant surface. Titanium dioxide-blasted implants have shown multiple clinical successes, including improved bone-to-implant contact (BIC) [7-9], high clinical success rates after 10 years [10,11] and higher marginal bone levels and survival rates $[12,13]$.

Despite such successes, a recent systematic review [14] analyzed the clinical results from 16 randomized clinical trials (RCTs) and summarized that no particular implant 
type had superior long-term success. However, none of these RCTs involved implants that were either made or coated with materials other than $\mathrm{Ti}$; as such, this review may provide additional motivation for research involving non-titanium implant coatings. For example, plasmasprayed $\mathrm{CaP}$ coatings have been evaluated with varying degrees of success. Several studies have demonstrated clinical failures [15-17] due to coating delamination which results from the differences in dissolution behavior of amorphous and crystalline $\mathrm{CaP}$ phases. However, a larger systematic review [18] actually showed no difference in long-term success between plasma-sprayed $\mathrm{CaP}$ coatings and traditional Ti implants.

Alternatively, metal oxides may be used on artificial implants since these types of coatings can incorporate the robust mechanical properties of the base metal with the biocompatibility of the oxide layer [19]. Prior experiments using niobium $(\mathrm{Nb})$ metal as a base demonstrated bioactivity of the anodized niobium oxide coating in a variety of solutions including calcium-phosphorous solution [20], simulated and human salivas [21] and simulated blood fluid [22]. A small lattice mismatch of only $1.1 \%$ between the $\mathrm{Nb}_{2} \mathrm{O}_{5}$ oxide phase and hydroxyapatite suggested an epitaxial influence on mineral nucleation [20]. Additionally, the surface roughness of the oxide coatings increased proportional to anodization time [23]. The same $\mathrm{Nb}_{2} \mathrm{O}_{5}$ microcone morphology was also generated when smooth Ti alloy implants were coated with $\mathrm{Nb}$ and then anodized [24].

These studies (including a recently completed in vivo study demonstrating superior osseointegration of niobium oxide-coated smooth $\mathrm{Ti}$ implants relative to smooth Ti implant controls) have contributed to the scope of the utility of the niobium oxide morphology as a viable coating, but have not yet involved studies on roughened Ti surfaces. Combining the structured niobium oxide morphology with the rough framework of a sand-blasted titanium oxide coating attractive for cellular attachment and growth may provide an opportunity to ultimately improve bone apposition. Thus, it is necessary to explore whether niobium oxide can be generated on the surface of a roughened Ti implant. Therefore, the purpose of this study was to determine the feasibility of creating a niobium oxide coating on a commercially available sandblasted Ti alloy (SB-Ti) dental implant.

\section{Material and Method}

SB-Ti dental implant screws (IMTEC Item \# SH-10, 3M IMTEC, Ardmore, OK) were $1.8 \mathrm{~mm}$ in diameter and 10 $\mathrm{mm}$ in height and featured a collared MDI implant standard thread design with a square prosthetic head. $\mathrm{Nb}$ coatings were then applied by sputter coating at a base pressure of $5 \times 10^{-7}$ Torr to generate a smooth $5 \mu \mathrm{m} \mathrm{Nb}$ coating.

Anodization was then performed using the Karlinsey method [25], as shown in Figure 1(A). Table 1 summarizes the anodization condition of 7 implant screws. Hydrofluoric acid $(48 \%$ - 50\% assay, Fisher Scientific, Pittsburgh, PA, USA) was added to a Nalgene beaker containing deionized (DI) water. The total solution volume was always $100 \mathrm{~mL}$, with $\mathrm{HF}_{(\mathrm{aq})}$ concentrations ranging from $0.1 \%$ to $0.5 \%$. $100 \mathrm{mg} \mathrm{NaF}$ (Spectrum Chemical Mfg. Corp., Gardena, CA, USA) was added and the solution was magnetically stirred at $30^{\circ} \mathrm{C}$ for one hour prior to anodization using a Cimarec digital stirring hotplate (Barnstead International, Dubuque, IA, USA). Next, a copper electrode was connected to a Sorensen DLM 300-2 power supply (AMETEK Programmable Power, Inc., San Diego, CA, USA) and placed into the same beaker. An alligator clip was used to connect the implant screw and immerse the threads in the solution (Figures 1(B) and (C)). Finally, a constant $25 \mathrm{~V}$ potential was supplied to stimulate oxide development. All anodizations were performed with constant stirring and the

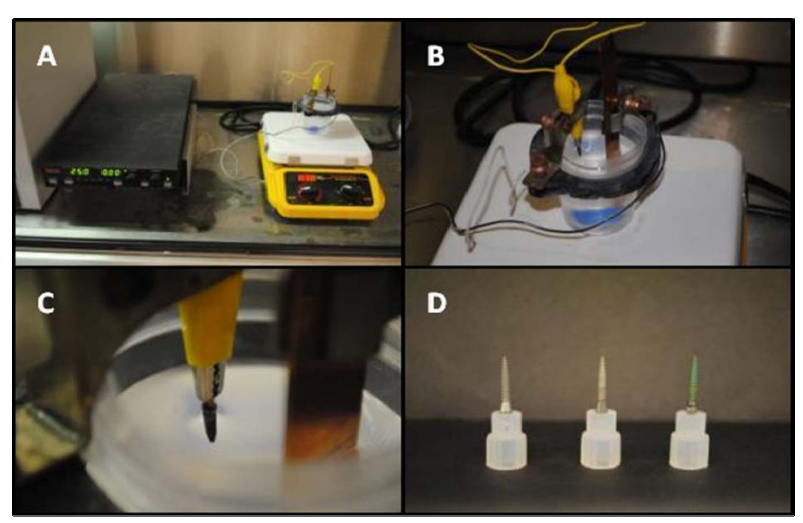

Figure 1. Image (A) depicts the entire anodization setup, including the electrochemical cell, stir plate, and power supply. Image (B) provides a closer view of the electrochemical cell itself while image (C) shows how the implant screw is immersed into solution by an alligator clip. Image (D) shows, from left to right, an uncoated implant and an Nbcoated implant before and after anodization.

Table 1. Implant anodization parameters and resulting surface conditions.

\begin{tabular}{cccccc}
\hline ID & $\begin{array}{c}\text { Nb Coating } \\
(\mu \mathrm{m})\end{array}$ & $\begin{array}{c}{\left[\mathrm{HF}_{(\mathrm{aq})}\right]} \\
(\mathrm{wt} \%)\end{array}$ & $\begin{array}{c}\text { Time } \\
(\mathrm{hrs})\end{array}$ & $\begin{array}{c}\text { Coating } \\
\text { Delamination }\end{array}$ & $\begin{array}{c}\text { Oxide } \\
\text { Growth? }\end{array}$ \\
\hline $\mathrm{A}$ & $\mathrm{N} / \mathrm{A}$ & 0.5 & 2 & $\mathrm{~N} / \mathrm{A}$ & N/A \\
$\mathrm{B}$ & 5 & 0.5 & 2 & Complete & No \\
$\mathrm{C}$ & 5 & 0.25 & 2 & Moderate & Yes \\
$\mathrm{D}$ & 5 & 0.25 & 1 & Light & Yes \\
E & 5 & 0.1 & 2 & Light & Yes \\
F & 5 & 0.1 & 1 & None & Yes \\
\hline
\end{tabular}


hotplate set to $30^{\circ} \mathrm{C}$. When anodization was terminated, the screw was removed from the alligator clip, rinsed with DI water for 10 seconds, and allowed to air dry.

Anodized implant screws were then analyzed using a Jeol JSM-5310LV Scanning Electron Microscope (SEM). The working distance was kept between 10 - $12 \mathrm{~mm}$ with an accelerating voltage of $20 \mathrm{kV}$. The magnification was increased from $100 \times$ up to $10,000 \times$.

\section{Results and Discussion}

\subsection{Anodization and Delamination}

Previous experiments [23] demonstrated that a minimum anodization time of 1 hour was required to stimulate noticeable oxide development on dental implant screws. Therefore, 1 hour was used as a baseline and 2 hours was used to demonstrate the trends observed with increased anodization time. When comparing the images of Figures 2(C) with (D) $\left(0.25 \% \mathrm{HF}_{(\mathrm{aq})}\right)$ and (E) with (F) $\left(0.1 \% \mathrm{HF}_{(\mathrm{aq})}\right)$, it is clear that increasing anodization time at a constant $\mathrm{HF}_{(\mathrm{aq})}$ concentration results in more extensive coating delamination. Similarly, when comparing Figures 2(C) to (E) (2 hr anodization) and (D) with (F) (1 hour anodization), the delamination increases with higher $\mathrm{HF}_{(\mathrm{aq})}$ concentration at a constant anodization time. The comparison of Figures 2(A) and (B) definitively shows that the $\mathrm{Nb}$ coating is completely removed after a $2 \mathrm{hr}$ anodization in $0.5 \% \mathrm{HF}_{(\mathrm{aq})}$.

\subsection{Anodization and Oxide Growth}

As for the oxide growth, Figures 3(C) and (D) in par- ticular show that growth increases with anodization time at a given $\mathrm{HF}_{(\mathrm{aq})}$ concentration. The relationships between Figures 3(C) and (E) along with (D) and (F) show that oxide growth is more substantial at lower $\mathrm{HF}_{(\mathrm{aq})}$ concentrations when the anodization time is held constant.

$\mathrm{HF}_{(\mathrm{aq})}$ is necessary to generate the $\mathrm{Nb}_{2} \mathrm{O}_{5}$ oxide structure previously observed using this anodization process, as the same oxide morphology has not been observed using different electrolyte solutions such as oxalic acid, sulfuric acid, phosphoric acid, and nitric acid [26]. It is believed that $\mathrm{F}^{-}$ions cut into the $\mathrm{Nb}$ metal during oxidation and assist with the development of the $\mathrm{Nb}_{2} \mathrm{O}_{5}$ structure when oxygen ions interact with interstitial $\mathrm{Nb}$ ions [21,27]. The previously proposed growth model [28] depicts $\mathrm{O}$ solution into the $\mathrm{Nb}$ metal and initial $\mathrm{Nb}_{6} \mathrm{O}$ segregation to relax the induced lattice strain. However, the subsequent $\mathrm{Nb}_{2} \mathrm{O}_{5}$ nucleation is accompanied by a factor 3 volume increase which strains and serrates the underlying metal and generates defects. These defects in turn enhance $\mathrm{O}$ diffusion and can lead to further oxide growth.

\section{Conclusion}

At longer anodization times, it is possible that the additional oxide growth and associated $\mathrm{Nb}$ deformation could destabilize the $\mathrm{Nb}$ - $\mathrm{Ti}$ interface and result in coating delamination. As for the role of $\mathrm{HF}_{(\mathrm{aq})}$ concentration, both $\mathrm{Nb}$ metal and $\mathrm{Nb}_{2} \mathrm{O}_{5}$ oxide are soluble in $\mathrm{HF}_{(\mathrm{aq})}$ [28]. Therefore, while $\mathrm{HF}_{(\mathrm{aq})}$ aids in $\mathrm{Nb}_{2} \mathrm{O}_{5}$ development as mentioned, it also produces a rate of oxide dissolution

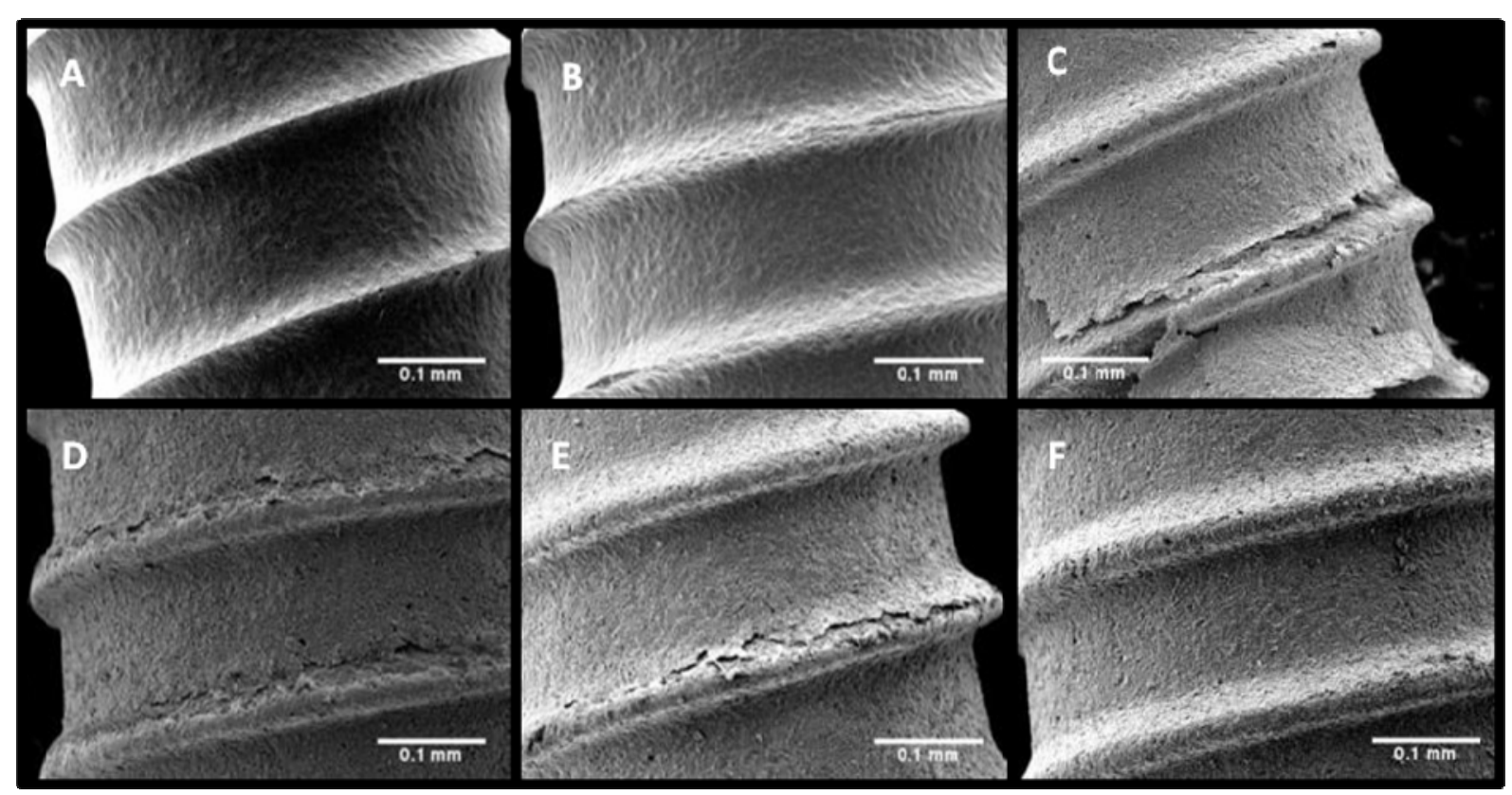

Figure 2. Low magnification $(100 \times)$ SEM images of implants (A)-(F) depict the effects of anodization time and $\mathrm{HF}_{(\mathrm{aq})}$ concentration on coating delamination. 


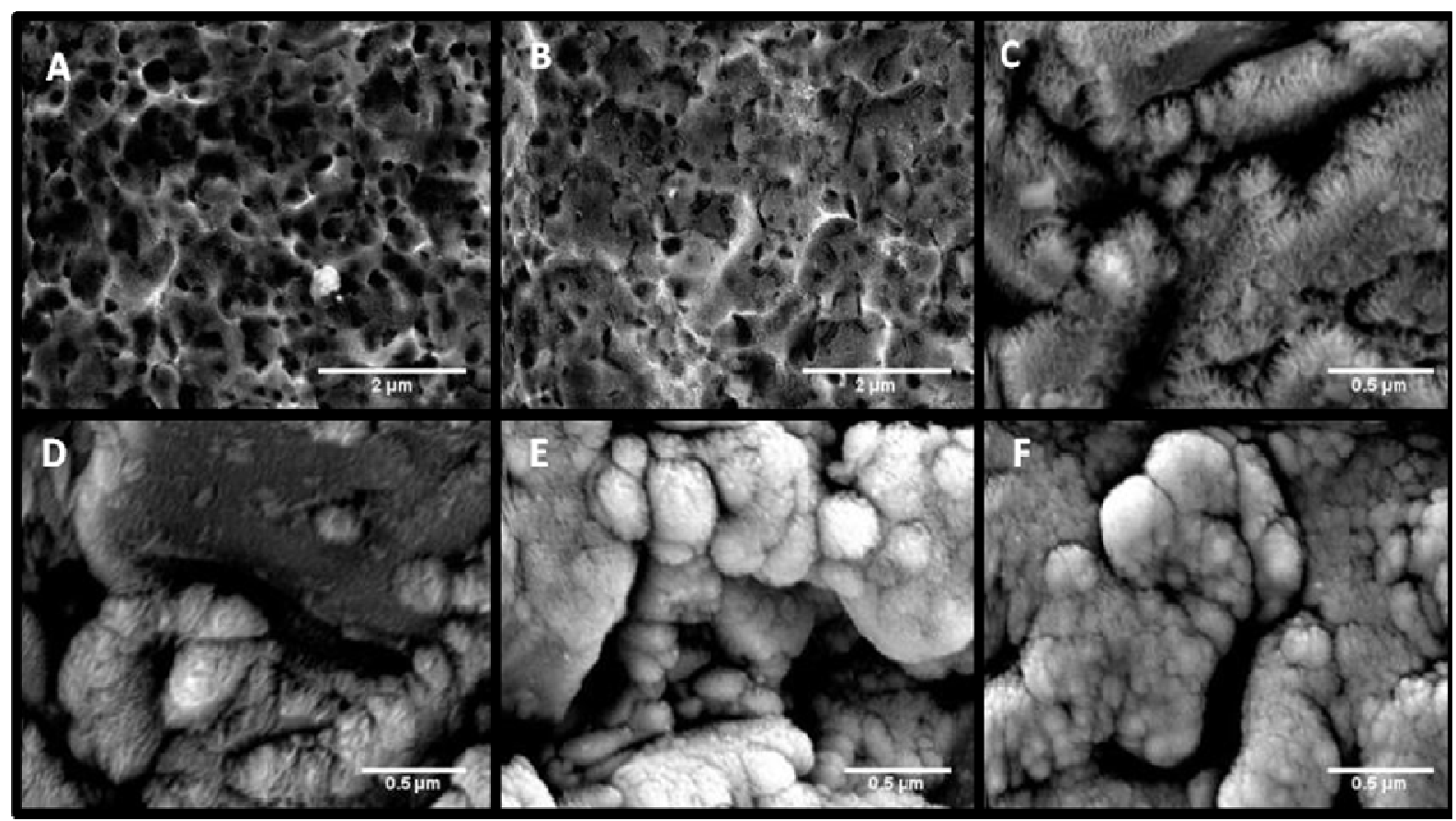

Figure 3. High magnification SEM images of implants (A)-(F) at $3500 \times((A),(B))$ and 10,000× (C)-(F) demonstrate the effects of anodization time and $\mathrm{HF}_{(\mathrm{aq})}$ concentration on niobium oxide growth.

proportionate to acid concentration. This property may help to explain why more extensive oxide coverage was observed at $0.1 \% \mathrm{HF}_{(\mathrm{aq})}$ than $0.25 \% \mathrm{HF}$ and no oxide growth was seen for $0.5 \% \mathrm{HF}_{(\mathrm{aq})}$. Based on these results, it is evident that a balance must be struck between increasing oxide growth without producing coating delamination. Since longer anodization times help with growth but are hindered by delamination, lowering $\mathrm{HF}_{(\mathrm{aq})}$ concentrations was an effective way to avoid undesirable delamination. For these reasons, implant " $F$ ", prepared using a $1 \mathrm{hr}$ anodization time at $0.1 \% \mathrm{HF}_{(\mathrm{aq})}$, was deemed to have the optimal surface morphology for future laboratory and in vivo evaluations.

\section{Acknowledgements}

We kindly acknowledge 3M ESPE for providing the implant screws for this study. This work was partially supported by NIH/NIDCR grant R43DE019034-01A1 and State of Indiana grant No. 282.

\section{REFERENCES}

[1] L. Le Guéhennec, A. Soueidan, P. Layrolle and Y. Amouriq, "Surface Treatments of Titanium Dental Implants for Rapid Osseointegration," Dental Materials, Vol. 23, No. 7, 2007, pp. 844-854. doi:10.1016/j.dental.2006.06.025

[2] C.C. Montes, F.A. Pereira, G. Thome, et al., "Failing Factors Associated with Osseointegrated Dental Implant Loss," Implant Dentistry, Vol. 16, No. 4, 2007, pp. 404-

\section{8. doi:10.1097/ID.0b013e31815c8d31}

[3] R. Junker, A. Dimakis, M. Thoneick and J. Jansen, "Effects of Implant Surface Coatings and Composition on Bone Integration: A Systematic Review," Clinical Oral Implants Research, Vol. 20, No. S4, 2009, pp. 185-206. doi:10.1111/j.1600-0501.2009.01777.x

[4] G. Mendonça, D. B. S. Mendonça, F. J. L. Aragao and L. F. Cooper, "Advancing Dental Implant Surface Technology-From Micron- to Nanotopography," Biomaterials, Vol. 29, No. 28, 2008, pp. 3822-3835. doi:10.1016/j.biomaterials.2008.05.012

[5] P. P. Binon, "Implants and Components: Entering the New Millennium," International Journal of Oral and Maxillofacial Implants, Vol. 15, No. 1, 2000, pp. 76-94.

[6] T. Albrektsson, P. I. Branemark, H. A. Hansson and J. Lindstrom, "Osseointegrated Titanium Implants Requirements for Ensuring a Long-Lasting, Direct Bone-to-Implant Anchorage in Man," Acta Orthopaedica Scandinavica, Vol. 52, No. 2, 1981, pp. 155-170.

[7] C. J. Ivanoff, C. Hallgren, G. Widmark, L. Sennerby and A. Wennerberg, "Histologic Evaluation of the Bone Integration of $\mathrm{TiO}_{2}$ Blasted and Turned Titanium Microimplants in Humans," Clinical Oral Implants Research, Vol. 12, No. 2, 2001, pp. 128-134. doi:10.1034/j.1600-0501.2001.012002128.x

[8] K. Gotfredsen, A. Wennerberg, C. Johansson, L. T. Skovgaard and E. Hjorting-Hansen, "Anchorage of TiO2Blasted, HA-Coated, and Machined Implants: An Experimental Study with Rabbits," Journal of Biomedical Materials Research, Vol. 29, No. 10, 1995, pp. 1223-1231. doi:10.1002/jbm.820291009

[9] L. Rasmusson, K. E. Kahnberg and A. Tan, "Effects of 
Implant Design and Surface on Bone Regeneration and Implant Stability: An Experimental Study in the Dog Mandible," Clinical Implant Dentistry and Related Research, Vol. 3, No. 1, 2001, pp. 2-8. doi:10.1111/j.1708-8208.2001.tb00123.x

[10] K. Gotfredsen and U. Karlsson, "A Prospective 5-Year Study of Fixed Partial Prostheses Supported by Implants with Machined and $\mathrm{TiO}_{2}$-Blasted Surface," Journal of Prosthodontics, Vol. 10, No. 1, 2001, pp. 2-7.

[11] L. Rasmusson, J. Roos and H. Bystedt, "A 10-Year Follow-Up Study of Titanium Dioxide-Blasted Implants," Clinical Implant Dentistry and Related Research, Vol. 7, No. 1, 2005, pp. 36-42.

[12] D. van Steenberghe, G. De Mars, M. Quirynen, R. Jacobs and I. Naert, "A Prospective Split-Mouth Comparative Study of Two Screw-Shaped Self-Tapping Pure Titanium Implant Systems," Clinical Oral Implants Research, Vol. 11, No. 3, 2000, pp. 202-209. doi:10.1034/j.1600-0501.2000.011003202.x

[13] P. Astrand, B. Engquist, S. Dahlgren, E. Engquist, H. Feldmann and K. Grondahl, "Astra Tech and Branemark System Implants: A Prospective 5-Year Comparative Study. Results after One Year," Clinical Implant Dentistry and Related Research, Vol. 1, No. 1, 1999, pp. 1726. doi:10.1111/j.1708-8208.1999.tb00087.x

[14] M. Esposito, L. Murray-Curtis, M. G. Grusovin, P. Coulthard and H.V. Worthington, "Interventions for Replacing Missing Teeth: Different Types of Dental Implants," Cochrane Database Systematic Reviews, Vol. 25, No. 1, 2007. doi:10.1002/14651858.CD003815

[15] S. Wheeler, "Eight-Year Clinical Retrospective Study of Titanium Plasma-Sprayed and Hydroxyapatite-Coated Cylinder Implants," International Journal of Oral and Maxillofacial Implants, Vol. 11, No. 3, 1996, pp. 340-350.

[16] Y. L. Chang, D. Lew, J. B. Park and J. C. Keller, "Biomechanical and Morphometric Analysis of Hydroxyapatite-Coated Implants with Varying Crystallinity," Journal of Oral and Maxillofacial Surgery, Vol. 57, No. 9, 1999, pp. 1096-1108. doi:10.1016/S0278-2391(99)90333-6

[17] D. Tinsley, C. Watson and J. Russell, "A Comparison of Hydroxylapatite Coated Implant Retained Fixed and ReMovable Mandibular Prostheses over 4 to 6 Years," Clinical Oral Implants Research, Vol. 12, No. 2, 2001, pp. 159-166. doi:10.1034/j.1600-0501.2001.012002159.x

[18] J. Lee, L. Rouhfar and O. Beirne, "Survival of Hydroxya-
patite-Coated Implants: A Meta-Analytic Review," Journal of Oral and Maxillofacial Surgery, Vol. 58, No. 2, 2000, pp. 1372-1379. doi:10.1053/joms.2000.18269

[19] T. Kokubo, H. M. Kim and M. Kawashita, "Novel Bioactive Materials with Different Mechanical Properties," Biomaterials, Vol. 24, No. 13, 2003, pp. 2161-2175. doi:10.1016/S0142-9612(03)00044-9

[20] R. L. Karlinsey, K. Yi and C. W. Duhn, "Nucleation and Growth of Apatite by a Self-Assembled Polycrystalline Bioceramic," Bioinspiration \& Biomimetics, Vol. 1, No. 1, 2006, pp. 12-19. doi:10.1088/1748-3182/1/1/002

[21] R. L. Karlinsey, A. T. Hara, K. Yi and C. W. Duhn, "BioActivity of Novel Self-Assembled Crystalline $\mathrm{Nb}_{2} \mathrm{O}_{5}$ Microstructures in Simulated and Human Salivas," Biomedical Materials, Vol. 1, No. 1, 2006, pp. 16-23. doi:10.1088/1748-6041/1/1/003

[22] R. L. Karlinsey and K. Yi, "Self-Assembly and Bioactive Response of a Crystalline Metal Oxide in a Simulated Blood Fluid," Journal of Materials Science: Materials in Medicine, Vol. 19, No. 3, 2007, pp. 1349-1354. doi:10.1007/s10856-007-3164-9

[23] A. Mackey, R. L. Karlinsey, A. Chern and T. G. Chu, "The Growth Kinetics and in Vitro Biocompatibility of $\mathrm{Nb}_{2} \mathrm{O}_{5}$ Microcones," International Journal of Medical Engineering and Informatics, Vol. 2, No. 3, 2010, pp. 247-260. doi:10.1504/IJMEI.2010.035218

[24] A. C. Mackey, R. L. Karlinsey, T. G. Chu and D. Alge, "Optimized Anodization Conditions for Niobium-Coated Titanium-Alloy Implant Screws," Journal of Dental Research, Vol. 90, 2011, p. 608.

[25] R. L. Karlinsey, "Self-Assembled $\mathrm{Nb}_{2} \mathrm{O}_{5}$ Microcones with Tailored Crystallinity," Journal of Materials Science, Vol. 41, No. 15, 2006, pp. 5017-5020. doi:10.1007/s10853-006-0135-3

[26] I. Sieber, H. Hildebrand, A. Friedrich and P. Schmuki, "Formation of Self-Organized Niobium Porous Oxide on Niobium," Electrochemistry Communications, Vol. 7, No. 1, 2005, pp. 97-100. doi:10.1016/j.elecom.2004.11.012

[27] R. L. Karlinsey, "Preparation of Self-Organized Niobium Oxide Microstructures via Potentiostatic Anodization," Electrochemistry Communications, Vol. 7, No. 12, 2005, pp. 1190-1194. doi:10.1016/j.elecom.2005.08.027

[28] J. Halbritter, "On the Oxidation and on the Superconductivity of Niobium," Applied Physics A, Vol. 43, No. 1, 1987, pp. 1-28. doi:10.1007/BF00615201 